\title{
Optimisation of Arsenic Adsorption from Water by Carbon Nanofibres Grown on Powdered Activated Carbon Impregnated with Nickel
}

\author{
A.A. Mamun ${ }^{* 1}$, F.R. Ma'an', A.K. Zahirah ${ }^{1}$, M.A. Yehya ${ }^{1}$, A.R.S. Mohammed ${ }^{1}$, \\ M.Z. Alam ${ }^{1}$, S.A. Muyibi ${ }^{1}$, I.A. Faris ${ }^{2}$ and I. Azni ${ }^{3}$. \\ ${ }^{1}$ Bioenvironmental Engineering Research Unit (BERU), Faculty of Engineering, International Islamic \\ University Malaysia, Jalan Gombak, 53100 KL, Malaysia. \\ ${ }^{2}$ Department of Manufacturing Engineering, ioenvironmental Engineering Research Unit (BERU), Faculty \\ of Engineering, International Islamic University Malaysia, Jalan Gombak, 53100 KL, Malaysia. \\ ${ }^{3}$ Deprtment of Chemical \& Environmental Engineering, Faculty of Engineering Universiti Putra Malaysia, \\ 43400 UPM, Serdang, Selangor, Malaysia \\ Email: mamun@iium.edu.my
}

\begin{abstract}
Contamination of water due to arsenic (As) is increasing in many parts of the world. The removal of As from aqueous solution by using impregnated Carbon Nanofibres (CNFs) as the adsorbent is reported in this paper. The effects of $\mathrm{pH}, \mathrm{CNFs}$ dosage, contact time and initial concentration of arsenic were studied at room temperature $\left( \pm 25^{\circ} \mathrm{C}\right)$. The interactions among the parameters were also investigated. The data obtained from the adsorption experiment were analysed using statistical software in order to develop a regression equation to represent the optimum operating conditions. The interactions of each parameters were considered during this analysis and the result indicated that the highest removal $(97.25 \%)$ of As can be attained at $\mathrm{pH} \mathrm{6}$, initial concentration of arsenic of $0.08 \mathrm{mg} / \mathrm{L}$, contact time of $60 \mathrm{~min}$ and CNF dosage of $200 \mathrm{mg} / \mathrm{L}$. Comparison between impregnated CNF and Powdered Activated Carbon (PAC) were also done and it is determined that impregnated CNF has better removal compared to PAC alone. The final concentration of As after the treatment using CNFs was about $8 \sim 10$ times less than that of using PAC. Therefore, it can be concluded that CNFs are highly potential for the adsorption of As from water.
\end{abstract}

Keywords: Adsorption, Arsenic, Carbon Nanofibres, Optimum Condition and Impregnated Powdered Activated Carbon.

\section{Introduction}

Heavy metals are natural components of the Earth's crust and they could not be degraded or destroyed. To a small extent they enter our bodies via food, drinking water and air. Heavy metals are dangerous because they tend to bioaccumulate, which means an increase in the concentration of a chemical in a biological organism over time, compared to the chemical's concentration in the environment (Smith, 2000). Heavy metals can enter a water supply by industrial and consumer waste, or even from acidic rain breaking down soils and releasing heavy metals into streams, lakes, rivers, and groundwater.

Basically, arsenic is a semi-metal element in the periodic table. It is odorless and tasteless. It enters drinking water supplies from natural deposits in the earth or activities such as from agricultural and industrial practices (Mazumder, 2000). Arsenic is a poisonous element which could lead to health effects to human beings. The presence of arsenic in the drinking water can be considered dangerous because of the large quantity of water consumed by the human beings in long term. Therefore, an increasing awareness has been focused on the removal of arsenic from water due to its detrimental effects on human health.

There are different approaches to remove arsenic from aqueous solution, including chemical precipitation, ion exchange, coagulation, oxidation and adsorption. Adsorption method is reported to be the most common method used to remove arsenic from water and wastewater treatment due to its simplicity and cost effectiveness (Volesky, 2005). Various adsorbents have been used to remove arsenic from aqueous solution such as activated carbon, iron oxides, granular titanium dioxide, natural iron ores, and bead cellulose.

It was reported that CNFs have high adsorption capacity and can be used as an adsorbent for removal of arsenic from aqueous solution (Chatterjee, 2002). Therefore, this study intended to examine the removal of arsenic from aqueous solution using CNFs grown on Powdered Activated Carbon (PAC).

\section{Materials and methods}

Powdered activated carbons $(100-250 \mu \mathrm{m})$ were impregnated with $\mathrm{Ni}$ catalyst and CNFs were synthesized on the PACs using chemical vapour deposition (CVD) method. 
Field Emission Scanning Electron Microscopy (FESEM) was used to determine the morphology of the CNFs in terms of diameter, length and coverage on the PACs.

Experiments were conducted at room temperature $\left( \pm 25{ }^{\circ} \mathrm{C}\right)$ to study the effect of $\mathrm{pH}, \mathrm{CNFs}$ dosage, contact time and initial concentration of arsenic on the adsorption of As ions. Each experiment was conducted in $100 \mathrm{ml}$ shake flask. The prepared arsenic stock solutions with adjusted $\mathrm{pH}$ value were placed into the $100 \mathrm{ml}$ shake flasks. Different concentration ranges from 100 to $300 \mathrm{mg} / \mathrm{L}$ of Carbon Nanofibres were added to the stock solution respectively (Table 1). The shake flasks containing the mixtures at different $\mathrm{pH}$ were shaken at $150 \mathrm{rpm}$ using a mechanical shaker. These mixtures were shaken according to the contact time $(10,30,60,90$ and 110 min). The maximum limit of the initial concentrations of arsenic was selected based on the Department of Environment (DOE) Malaysia effluent discharge standard.

The adsorbents were removed from the solution by filtration using filter paper $(110 \mathrm{~mm})$. The solutions were analyzed using Atomic Absorption Spectroscopy (Graphite Furnace) at wavelengths of $193.70 \mathrm{~nm}$ for arsenic. Finally, the final concentration of each study was tabulated in order to determine the percentage removal of As by CNFs.

Table 1: Experimental parameters and its variation

\begin{tabular}{|c|l|c|c|c|c|c|}
\hline \multirow{2}{*}{ No } & \multirow{2}{*}{ Parameter } & \multicolumn{5}{|c|}{ Level } \\
\cline { 3 - 7 } & & -2 & -1 & 0 & 1 & 2 \\
\hline 1 & $\mathrm{pH}$ & 4 & 5 & 6 & 7 & 8 \\
\hline 2 & $\begin{array}{l}\text { Initial } \\
\text { concentrati } \\
\text { on of } \\
\text { arsenic } \\
\text { (mg/L) }\end{array}$ & 0.06 & 0.07 & 0.08 & 0.09 & 0.10 \\
\hline 3 & $\begin{array}{l}\text { Contact } \\
\text { time } \\
\text { (minutes) }\end{array}$ & 10 & 30 & 60 & 90 & 110 \\
\hline 4 & $\begin{array}{l}\text { Adsorbent } \\
\text { dosage } \\
\text { (mg/L) }\end{array}$ & 100 & 150 & 200 & 250 & 300 \\
\hline
\end{tabular}

Design-expert Version 6.0.8 was used to conduct the experimental design for this test. Five parameters were used for the evaluation using Central Composite Design, which results in 33 experiment runs. For this project, 2 replications with 5 levels were used.

\section{Results and discussions}

The 3D response surface and the 2D contour plots are the graphical representation of the regression equation in order to determine the optimum values of the variables within the ranges considered. Both plots are presented in Figure 1.1 to Figure 1.3. The main goal of response surface is to find the optimum values of the variables such that the response is maximized (Alam, 2005). The maximum predicted value is indicated by the surface confined in the smallest ellipse in the contour diagram.

From Figure 1, the response surface was elliptical in the entire region. The maximum removal of arsenic was obtained at the point of intersection of major and minor axes of the ellipse. The maximum removal of arsenic was predicted at given ranges of both $\mathrm{pH}$ and contact time. At $\mathrm{pH} 6$ and contact time of $60 \mathrm{~min}$ showed the maximum removal of arsenic (i.e. minimum residual concentration of 0.0027 $\mathrm{mg} / \mathrm{L})$.

Similar interaction was observed in the effect of $\mathrm{pH}$ and adsorbent dosage at their centre and onward values (Figure 2). The highest removal of arsenic was observed with the interactions of $\mathrm{pH}$ and adsorbent dosage, 6 and $200 \mathrm{mg} / \mathrm{L}$ respectively.

The next observation was found in the effect of adsorbent dosage and contact time on maximum removal of arsenic at their centre and onward values (Figure 3). The highest removal of arsenic (at the residual of about $0.0027 \mathrm{mg} / \mathrm{L}$ ) was observed with the interactions of adsorbent dosage and contact time, $200 \mathrm{mg} / \mathrm{L}$ and $60 \mathrm{~min}$ respectively.

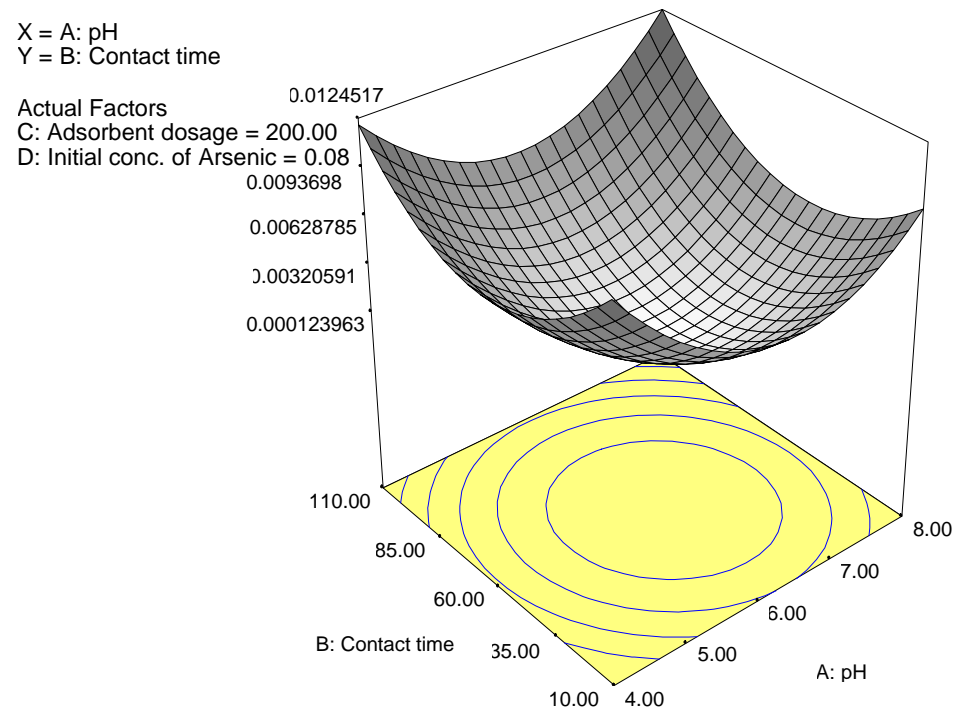

Figure 1: Response surface of the interaction of $\mathrm{pH}$ and contact time 
It is determined that the highest predictive percentage removal is $97.25 \%$. The parameters that contribute to these optimal conditions are initial concentration of arsenic of 0.08 $\mathrm{mg} / \mathrm{L}, \mathrm{pH}$ 6, contact time of $60 \mathrm{~min}$, adsorbent dosage of 200 $\mathrm{mg} / \mathrm{L}$, and agitation speed at $150 \mathrm{rpm}$. Based on these results, validation on removal of arsenic using optimum process conditions were done to compare and validate the results obtained.
Based on the results obtained, the experimental final concentration of arsenic and predicted final concentration of arsenic were plotted on the Figure 4 . It can be said that the experimental values and predicted values are very close to each other because as the $R^{2}$ reaches the value of 0.947 .

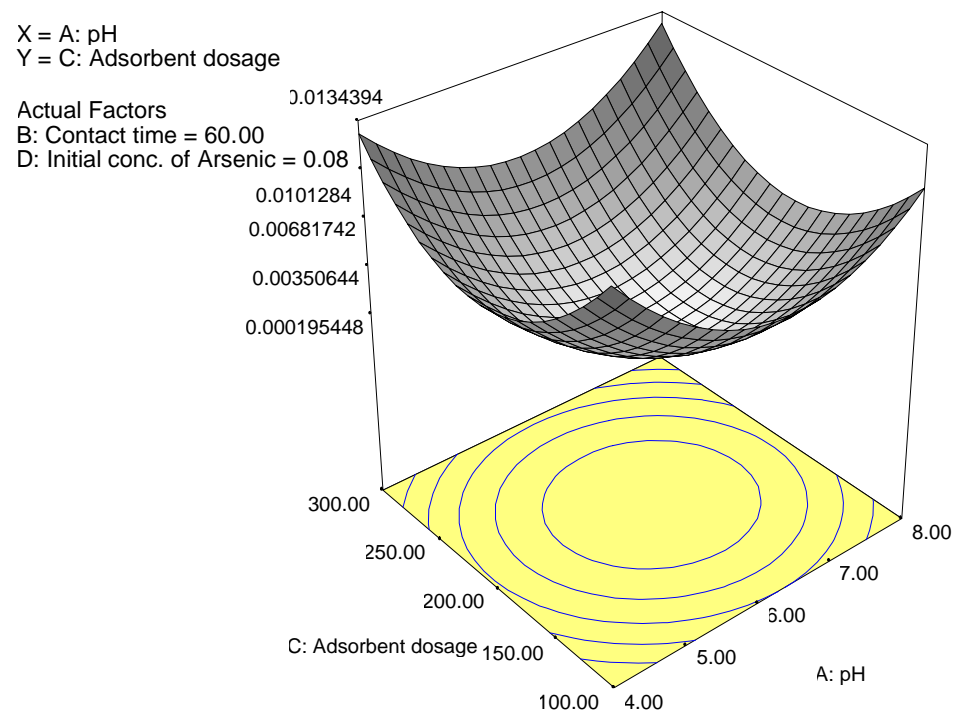

Figure 2: Response surface of the interaction of initial $p H$ and adsorbent dosage

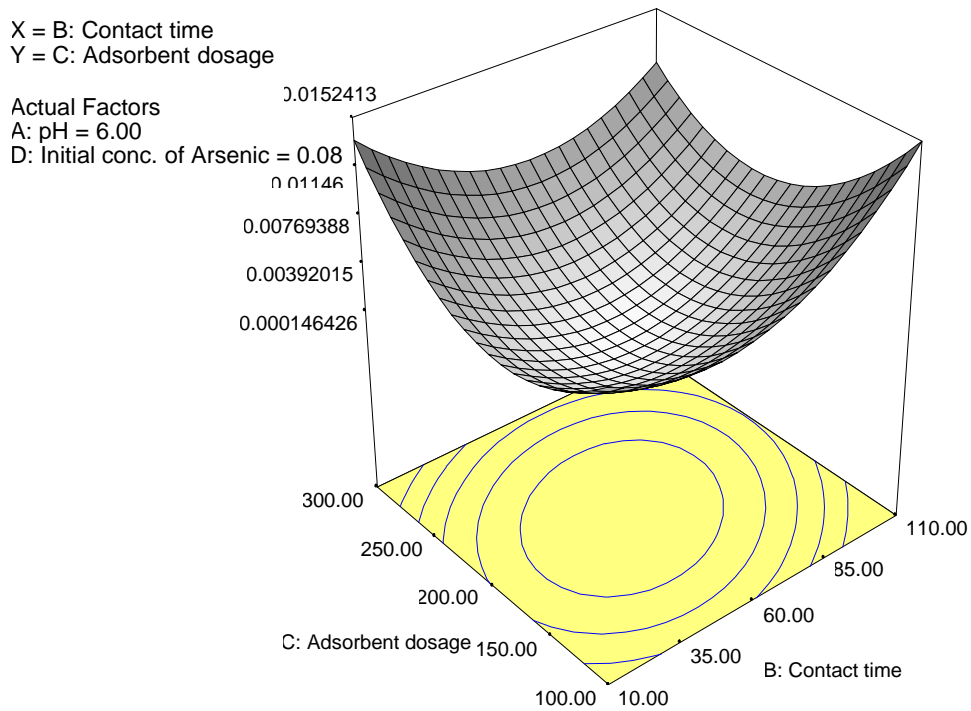

Figure 3: Response surface of the interaction of contact time and adsorbent dosage. 


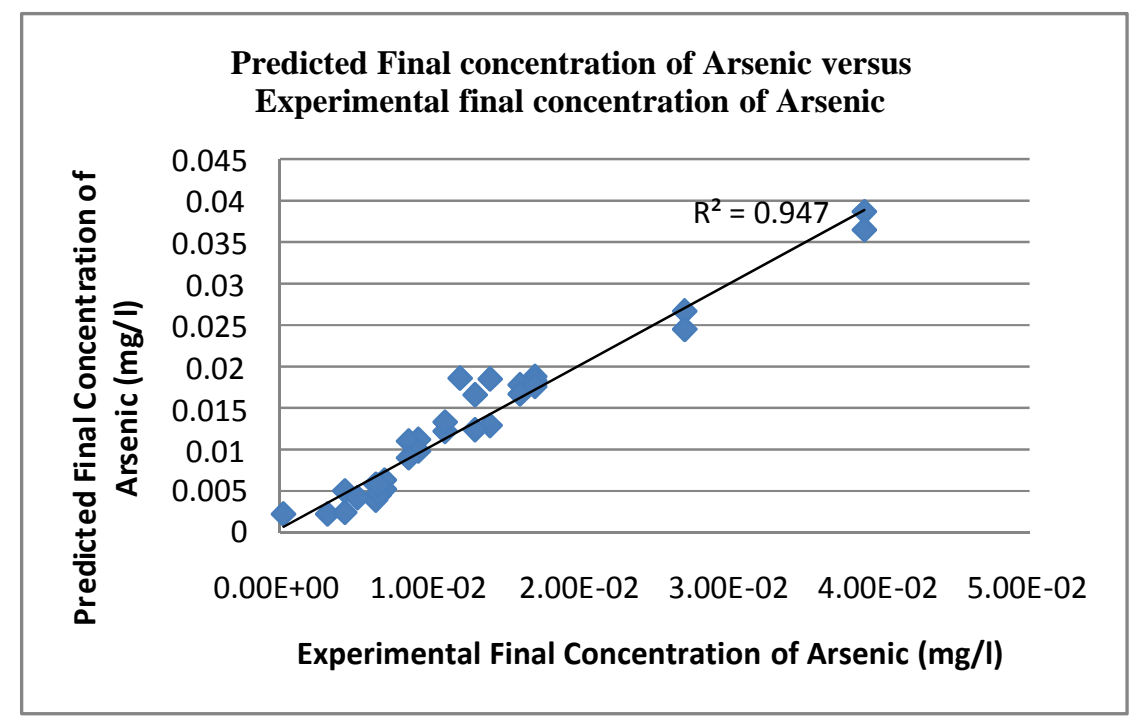

Figure 4: Relationship between the experimental final concentration and predicted final concentration of arsenic

The images of the CNFs grown on PACs before and after the adsorption tests are shown in Figure 5. It was observed that although the CNFs became smoother compared to the curly texture before the adsorption tests.
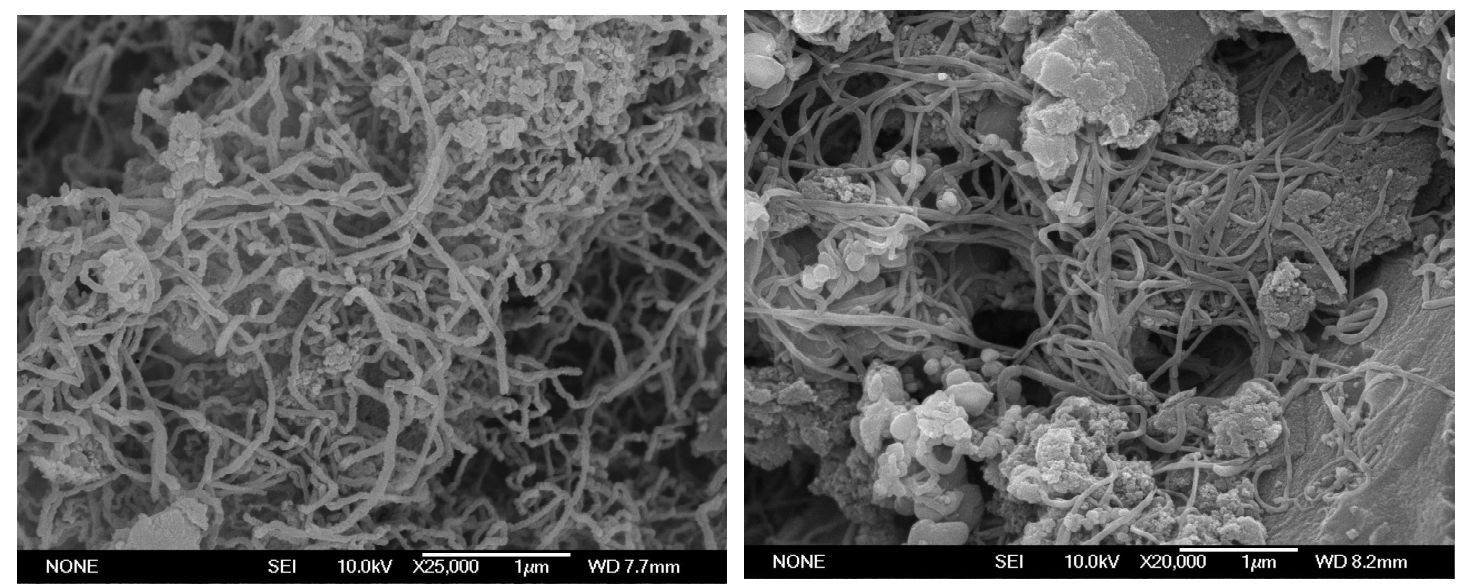

Figure 5: CNFs before (a) and after (b) the adsorption experiments

\section{Conclusion}

Carbon Nanofibres grown on PACs was found to be efficient for the adsorption of As in aqueous solution. The characterization of As ions uptake showed that the arsenic binding is dependent on the operational parameters such as $\mathrm{pH}, \mathrm{CNFs}$ dosage, contact time and initial concentration of arsenic.
Based on the study of the parameters used on the removal of As, the best conditions from each factor was fitted into the regression analysis in order to develop an optimization equation. The optimization equation was used to predict the highest percent removal of As. From this analysis, the highest (predictive) percent removal of $97.25 \%$ can be obtained for initial concentration of arsenic of $0.08 \mathrm{mg} / \mathrm{L}, \mathrm{pH}$ 6, contact time of $60 \mathrm{~min}, \mathrm{CNFs}$ dosage of $200 \mathrm{mg} / \mathrm{L}$ and agitation speed at $150 \mathrm{rpm}$. 


\section{References}

Abernathy, C.O. (2003). Arsenic: health effects, mechanisms of action and research issues. Journal of Workshop Summary, 121-133.

Adesola, N.A., Babalola, J.O., \& Sanni, R.A. (2006). Biosorption of lead ions from aqueous solution solution by maize leaf. Journal of Physics, 1(1), 23-26.

Alam M.Z., (2005). Optimization of citric acid by Empty Fruit Bunches. Journal of Biotechnology, 5(2) 145-196.,

Carbon Nanofiber. (2008). Retrieved

February 2, 2008 from http://en.wikipedia.org/wiki/

Carbon_nanofiber.

Chatterjee, A., \& Deopura, B.L. (2002). Carbon Nanotubes and Carbon Nanofibre: an overview. Journal for Fibers and Polymers, (3), 134-139.

Macphee, M.J. (2001). Treatment of arsenic residuals from drinking water removal processes. Environmental Engineering and Technology.

Martin, C.R. (2005). Nanomaterials: a membrane based synthetic approach. Journal of Nanomaterials, (266), 1961-1966.

Masciangioli, T., \& Zhang, W.X. (2003). Environmental Technologies at the Nanoscale. Environmental Science Technology, 102-108.

Mazumder, D.N. (2000). Arsenic in drinking water and the prevalence of respiratory effects in West Bengal, India. International Journal of Epidemology (29), 1047- 1052.

Namasivayam, C. (1998). Removal of arsenic from aqueous solution using industrial solid waste: adsorption rates and equilibrium studies. Ind. Eng. Chem. Res. (37), 4816-4822.

Petrusevski, B. (2007). Arsenic in drinking water. IRC International Water and SanitationCentre. 